\title{
Root Tensile Resistance of Selected Pennisetum Species and Shear Strength of Root-Permeated Soil
}

\author{
Afaff Emhemed Ettbeb, ${ }^{1,2}$ Zulfahmi Ali Rahman (D), ${ }^{1}$ Wan Mohd Razi Idris, ${ }^{1}$ Jumaat Adam, \\ S. Abd. Rahim, ${ }^{3}$ S. N. Ahmad Tarmidzi, ${ }^{1}$ and Tukimat Lihan' \\ ${ }^{1}$ Center of Earth Science and Environment, Faculty of Science and Technology, University Kebangsaan Malaysia, \\ 43600 Bangi, Malaysia \\ ${ }^{2}$ Biotechnology Department, Azzaytuna University, Tarhuna, Libya \\ ${ }^{3}$ Environmental Science Program, Faculty of Science and Natural Resources, Universiti Malaysia Sabah, Jalan UMS, \\ 88400 Kota Kinabalu, Sabah, Malaysia \\ Correspondence should be addressed to Zulfahmi Ali Rahman; zarah1970@ukm.edu.my
}

Received 5 August 2019; Revised 16 December 2019; Accepted 23 January 2020; Published 10 March 2020

Academic Editor: Davey Jones

Copyright ( $) 2020$ Afaff Emhemed Ettbeb et al. This is an open access article distributed under the Creative Commons Attribution License, which permits unrestricted use, distribution, and reproduction in any medium, provided the original work is properly cited.

\begin{abstract}
It is widely recognized that vegetation plays a significant role in contrasting slope instability through the root reinforcement. The main objectives of this paper are to evaluate the root tensile of selected Pennisetum species, namely, P. pedicellatum (PPd) and $P$. polystachion (PPl), and to determine the soil shear strength of root-permeated soil from these species. The selected species were initially planted in the polybags using the hydroseeding technique. A mineral fertilizer of NPK ratio $10: 8: 10$ was adopted in the hydroseeding mixture. Routine watering program was applied twice a day throughout growth observation for six months. Four replications were prepared for each species including a set of control polybags, which contained only soil for reference and comparison. The results of root tensile tests revealed the significant relationships between root diameter and tensile force. In comparison, the PPl was still indicated by higher values of root tensile force than PPd. The presence of roots clearly has contributed to the shear stress of root-permeated soils. The root density based on root biomass measurement attributed to the higher value of peak shear stress as achieved by PPl than PPd. The combined effects of root tensile and the soil shear strengths of this selected species can be used as biological materials in slope protection against erosion.
\end{abstract}

\section{Introduction}

Plants can play a vital role in controlling the soil erosion through their canopy and root networking. Soil erosion can happen at a very gentle slope and caused by erosion agents of water, wind, and others. In tropic regions, water is the main erosion agent that is responsible in extreme gully type of erosion up to soil landslides. These features are commonly associated with highly weathered barren soil and steep slopes with high annual rainfall [1]. High-intensity rainfall coupled with highly weathered soil may speed up soil saturation that leads to the loss of shear strength. Apart from that, removal or change in slope vegetation is among the control factors that also contribute to slope instability [2].
Soil-root interaction via vegetation can substantially improve slope stability as plants provide canopy (ground surface) and binding (subsurface) effects that contribute to soil shear strength. Many researchers reported that vegetation can play an important role in slope stabilization by strengthening of soil structure $[2,3]$. It is obviously a complex relationship between vegetation and soil reinforcement as they attribute to factors such as soil types, plant species and coverage, and soil moisture condition $[1,4]$. Past experiences show that slopes covered by vegetation pose less tendency of soil erosion due to water and wind actions [2, 5-7]. Vegetation contributes to slope stabilization through two different types of mechanisms: mechanical and hydrological mechanisms. From the mechanical point of 
view, plants can contrast soil instabilities by increasing soil shear strength through friction between root and soil particles as well as soil cohesiveness [8-10] (Rey et al., 2019; Stokes et al., 2007). Hydrologically, vegetation stimulates soil suction with evaporation, thus reducing soil moisture, which in turn delays the soil saturation time, limits the water leakage in the soil, and retains the soil dry [11]. A considerable improvement on soil shear strength of root-permeated soil has been linked to the distribution of root within the soil and the root tensile strength of particular root [12-15]. The relationship between root diameter and tensile strength is negatively correlated whilst root diameter is positively correlated with tensile resistance $[16,17]$. Mattia et al. [18] applied Wu [19] and Waldron [20] models to calculate the reinforcing effect in terms of increased shear strength of the soil. Later, Mao et al. [21] studied the root systems (root density, root orientation, and root tensile strength) and discussed the result in different models ( $\mathrm{Wu}$ and Waldron's Model (WWM) and Fiber Bundle Model (FBM)). De Baets et al. [22] examined the influences of root tensile strength and root distribution of some typical Mediterranean plant species on soil shear strength. They found that smaller diameter root has higher tensile strength and root from grass species can increase soil strength at topsoil but with the combination of shrub species, the soil can be improved up to the greater depth up to $0.5 \mathrm{~m}$. Fan and Chen [23] examined the effect of difference in root architecture on shear strength increment provided by plant roots in the soil. They found that plants with conspicuous oblique and vertical roots provide larger shear strength increment than that of root structures with copious lateral root system.

Various plant species have been studied for biological material in slope erosion control and slope stability [24-28]. Grasses have been a prevalent selection for slope erosion control as they can effectively offer surface coverage against rainfall impact and subsurface offer soil interparticle binding by plant root networking to increase the soil shear strength. Vetiver (Chrysopogon zizanioides) and signal grass (Brachiaria decumbens) are two common species used in slope management for improving the eroded slope areas. Vetiver has a unit long fibrous root networking that can reach up to $1 \mathrm{~m}$ deep into the soil profile. However, there are plenty of native plant species that can be highlighted due to their wide distribution and well adapted with local climate environment $[29,30]$. Plant species can be found locally which offer cheaper maintenance cost and can definitely tolerate local environments [31-33]. Besides that, the use of local species as biological materials in soil bioengineering applications can be added-value and economic in terms of cost reduction and compete with other products available in the market. There are still "unknown" herbs in terms of their biotechnological properties which can contribute to soil bioengineering and assess their potential impact on ecosystems to produce seed mixes, which, together with their usefulness in stabilizing the soil, can accelerate the plant dynamics [34].

Pennisetum spp. consists of more than a hundred species, belonging to the family Poaceae, fast-growing, perennial weed, and is widespread throughout Australia and the tropical mainland of Africa and Asia, including Malaysia
[35]. It has been regarded as an enemy to agricultural plants and uneconomically useful. The abundant presence of Pennisetum spp. reflects their successful adaption in local tropical environments and can be potentially adopted as biological materials in slope bioengineering approach. Hence, the main aims of this work are (i) to examine the effect of root tensile force of selected Pennisetum spp. (P. polystachion and P. pedicellatum) and (ii) to determine the shear strength of root-permeated soil. For the shear strength tests, control samples were also examined for reference purpose.

\section{Materials and Methods}

2.1. Plant Species and Soil. Two localized grass species were selected, namely, Pennisetum polystachion (PPl) and Pennisetum pedicellatum (PPd), in this study. Mature seeds of species were initially collected from the various sites in Universiti Kebangsaan Malaysia (UKM). The soil medium was obtained from a slope adjacent to the plot study site. The properties of soil are shown in Table 1 . It can be characterized as sandy clay loam (32.6\% clay $16.3 \%$ silt and $51 \%$ sand) with a highly acidic $\mathrm{pH}$. Meanwhile, the moisture and organic contents were $21 \%$ and $3.2 \%$, respectively.

Germination of each species was performed through hydroseeding technique in a polybag with a diameter of $22 \mathrm{~cm}$ and $24 \mathrm{~cm}$ in height. It contains a mixture of soil tackifier, seed, water, fertilizer, and paper mulch. The amount of each component is calculated according to the standard proposed by Hydroturf Services (M) Sdn. Bhd (Table 2). The fertilizer used in hydroseeding was a mineral fertilizer with NPK ratio of $10: 8: 10$. This ratio was used based on the growth performance of signal grass (Brachiaria decumbens) in preliminary study [36]. The results indicated that the signal grass showed successful growth in comparison with the NPK ratio of $5: 5: 7$.

In order to germinate the species, the hydroseeding slurry was manually and evenly sprayed on the soil surface of each polybag. Four replications were prepared for each species $\left(\mathrm{PPl}_{1}, \mathrm{PPl}_{4}\right.$ and $\left.\mathrm{PPd}_{1}, \mathrm{PPd}_{4}\right)$ including a set of control polybags, which contained only soil $\left(\mathrm{C}_{1}, \ldots, \mathrm{C}_{4}\right)$. This study was monitored for six months; both species were watered twice a day and left under glasshouse conditions with temperatures between $21^{\circ} \mathrm{C}$ and $32^{\circ} \mathrm{C}$, an average $12 \mathrm{~h}$ photoperiod, and relative humidity ranging between $60 \%$ and $90 \%$. Root and soil samples were then collected after six months of observation for further root characterization, tensile test, and determination of the soil shear strength.

2.2. Root Characteristics. Sampling of roots from both species was carried out after six months for root characterization. The parameters of root consisted of measurement of root diameter, length, and biomass. The polybags were torn out and the soil samples were carefully washed with tap water to remove all soil particles. Several root samples were selected for length measurement and the length of root was measured using universal tape meter. A vernier caliper was used to measure the diameters of the root at three different 
Table 1: Properties of the soils used in this study.

\begin{tabular}{lc}
\hline Parameters & Results \\
\hline $\mathrm{pH} \mathrm{H} \mathrm{H}_{2} \mathrm{O}(1: 2.5 ; \mathrm{w} / \mathrm{v})$ & $4.1 \pm 0.19$ \\
Soil organic matter $(\%)$ & $3.2 \pm 0.08$ \\
Soil water content $(\%)$ & $20.8 \pm 0.51$ \\
Sand $(\%)$ & $51 \pm 2.94$ \\
Clay (\%) & $33 \pm 1.24$ \\
Silt (\%) & $16 \pm 3.09$ \\
Soil texture & Sandy clay loam \\
$\mathrm{K}(\mathrm{mg} / \mathrm{kg})$ & $26.76 \pm 1.45$ \\
$\mathrm{P}(\mathrm{mg} / \mathrm{g})$ & $0.032 \pm 0.004$ \\
Total nitrogen $(\%)$ & $0.4 \pm 0.2$ \\
\hline
\end{tabular}

${ }^{*}$ Replicate soil samples of three are required for each test.

TABle 2: Proportion amount of hydroseeding mixture.

\begin{tabular}{lc}
\hline Materials & Amounts \\
\hline Seed $\left(\mathrm{g} / \mathrm{m}^{2}\right)$ & 27.5 \\
Paper mulch $\left(\mathrm{g} / \mathrm{m}^{2}\right)$ & 125.0 \\
Soil tackifier $(\mathrm{ml})$ & 3.0 \\
Fertilizer $\left(\mathrm{g} / \mathrm{m}^{2}\right)$ & 31.25 \\
Distilled water $(\mathrm{ml})$ & 300.0 \\
Average $\mathrm{pH}$ & 5.48 \\
\hline
\end{tabular}

points. Then, the root sample was placed into the oven for 48 hours at temperature of $60^{\circ} \mathrm{C}$. Then, the dried samples were weighted several times until the weight becomes constant with a balance (Model Mettle PJ3000, made in Japan). The root samples were then kept in a plastic bag for future reference.

2.3. Root Tensile Test. The tensile strength of the root can be expressed in terms of resistance or stress as the ratio of resistance and root area [37]. Many studies have provided data on the relationship between the tensile stress and root diameter which can be presented by an inverse power law equation $[18,22,37,38]$. Tensile stress is the ratio of maximum force to the cross-sectional area which derived from the root diameter at the rupture point as follows:

$$
T_{r}=\frac{4 F}{\pi d^{2}}
$$

where $T_{r}$ is tensile strength ( $\left.\mathrm{MPa}\right), F$ is the maximum load at the rupture point $(\mathrm{N})$, and $d$ is the average root diameter $(\mathrm{mm})$

Meanwhile, other authors preferred to express the tensile resistance-diameter relationship in terms of force unit [39-41]. Vergani et al. [37] stated that although there was no unique equation proposed, the commonly adopted form of a power law equation to represent the relationship between tensile force and diameter is as follows:

$$
T_{f}=\alpha \cdot d^{\beta},
$$

where $T_{f}$ is tensile force $(\mathrm{N})$ and $d$ is the average root diameter $(\mathrm{mm})$.

The tensile stress value is calculated by dividing the applied force by the cross-sectional area of the root at its rupture point [42]. However, the use of tensile force is probably preferable than tensile stress as the accurate measurement is difficult to be accurately determined for the root diameter at breaking force. In addition, the exact point of rupture also cannot be certain before the test especially for the fine and very fine roots. Generally, the point of rupture is established after the test and the diameter is reduced as a result of tensile strain and the rupture process is associated with a small proportion of the root rather than to a single infinitesimal section [37]. Therefore, the acceptable method for estimating the diameter is to measure the diameters at three different points along the root and then take average measurements [37, 41-45].

Root samples were taken from the polybags, which followed the same procedures for root biomass determination. In order to investigate the effect of different ages of the root on tensile resistance, root sampling was carried out after two and six months of growth period. Tensile test for individual root was carried out using the Universal Testing Machine (UTM) with the capacity of $50 \mathrm{~N}$ (Instron, Model 5566 , USA). The samples were cut into lengths of $10 \mathrm{~cm}$ before being weighed. The diameter of the root was recorded according to the method of root characteristics procedures. The two ends of the root were carefully wrapped using sand paper in accordance with ASTM D 3379-75 [46]. In order to achieve a superior grip with little risk of slippage during testing, the root was clamped into the entire wedge grip length. The root was pulled vertically up at a rate of $5 \mathrm{~mm} / \mathrm{min}$. The occurrence of extension until failure and reading of the force $(\mathrm{F})$ were recorded and generated automatically using the software that is linked to the UTM. The tensile force at the point of rupture was taken as the peak load $\left(F_{\text {Max }}\right)[37,41,42]$. The tensile force unit was recorded in Newton $(\mathrm{N})$. The relationship between tensile force and root diameter is expressed as shown in (1).

2.4. Direct Shear Test. The presence of plants on slope provides shelter to the soil surface against rainwater erosion while at subsurface level, slope can benefit from soil reinforcement through plant root. The impact of vegetation roots on the shear strength of soil can be considered as part of the cohesive strength aspect of the soil-root system [47]. Ideally, the shear strength of root-permeated soil creates surplus strength to the soil compared to a condition without the root.

The collection of soil sample applied a metal mould with sharp edges and pressed vertically into the soil surface. The mould was dug out carefully and was wrapped with plastic film in order to preserve the soil moisture content prior to laboratory tests. The sample was then trimmed carefully and fixed into brass box of shear box test $(60 \mathrm{~mm} \times 60 \mathrm{~mm} \times$ $25 \mathrm{~mm}$ ). This test follows the standards of British Standard Institution 1377 [48]. Each soil sample was applied with normal loads of $10 \mathrm{kPa}, 20 \mathrm{kPa}$, and $30 \mathrm{kPa}$ based on the values applied by previous researchers $[4,49,50]$. The samples were sheared horizontally at a strain rate of $1.2 \mathrm{~mm} / \mathrm{min}$. Mohr Coulumb's shear strength equation was used to calculate the cohesion and angle of friction of treated and control soils. In the presence of roots, the failure of soil should also take into account the failure of roots in the soil. 
Therefore, in this case the root is considered as reinforcement that increases the shear strength by $c_{r}[38,51-53]$ as follows:

$$
\tau=c_{s}+c_{r}+\sigma \tan \theta,
$$

where $c_{s}$ is the soil cohesion, $c_{r}$ is the root reinforcement, $\theta$ is the angle of friction, $\sigma$ is the normal load, and $\tau$ is the soil shear strength.

After the completion of the shearing, the moisture content and root biomass were determined for each sample. The sheared sample was weighed and transferred into the oven at $105^{\circ} \mathrm{C}$ for an overnight. Then, the sample $w$ was weighed again to measure the moisture content. The sample was gently washed to remove all the soil and the roots were put in a petri dish before being allowed to dry in the oven overnight at a temperature of $60^{\circ} \mathrm{C}$.

\section{Results and Discussion}

3.1. Root Characteristics. The root characteristics of both species are shown in Table 3 . There was a very slim difference in terms of diameter between PPl and PPd species. However, the root length for PPl species was higher than PPd species. A similar trend was also found for the root biomass of the PPl species $(50.28 \pm 9.39 \mathrm{~g})$. A significant increase in root length and root biomass that were observed in PPl species can contribute to a higher soil-root interaction. Subsequently, a great soil-root interaction will result in higher soil reinforcement that increases the shear strength of soil slope $[2,54]$. Root biomass increases the preferential path for the subsurface runoff, thus improving the soil shear strength and reducing slope failure [4]. On the other hand, preferential flow in the meadows promotes the accumulation of nutrients and can prevent the loss of organic matter. Previous studies reported that the preferential flow can prevent the absorption of water by the roots under low rainfall conditions and reduce runoff before the soil is saturated under high rainfall conditions [55-57]. Moreover, previous studies also showed that the vegetation recovery can highly increase the soil stability by accelerating plant growth and promoting soil formation processes such as fine soil particle collection, organic matter, and dispersal of mycorrhizas $[58,59]$.

\subsection{Root Tensile Resistance}

3.2.1. Tensile Force-Root Diameter Relationship. A total of thirty-two root samples from both species were collected after six months and were analyzed for the tensile strength test. The root diameters of the PPl and PPd species range from $0.21 \mathrm{~mm}$ to $1.1 \mathrm{~mm}$ and $0.25 \mathrm{~mm}$ to $1.2 \mathrm{~mm}$, respectively. The results of tensile force of the studied species are shown in Table 4 . The mean, maximum, and minimum values recorded for PPl species were 4.88, 9.33, and $1.06 \mathrm{~N}$, respectively. Meanwhile, for the PPd species, the mean, maximum, and minimum values recorded were $4.57,8.51$, and $1.14 \mathrm{~N}$, respectively. The PPl species exhibited a higher root tensile force if compared to that of the PPd species. The tensile force increased with increasing root diameter following a power function as shown in Figure 1.
TABLE 3: Root characteristics of the selected species.

\begin{tabular}{lccc}
\hline $\begin{array}{l}\text { Plant } \\
\text { species }\end{array}$ & $\begin{array}{c}\text { Root } \\
\text { diameter }(\mathrm{mm})\end{array}$ & $\begin{array}{c}\text { Root } \\
\text { length }(\mathrm{cm})\end{array}$ & $\begin{array}{c}\text { Root } \\
\text { biomass }(\mathrm{g})\end{array}$ \\
\hline PPl & $0.82 \pm 0.05$ & $42.67 \pm 2.05$ & $50.28 \pm 9.39$ \\
PPd & $0.84 \pm 0.06$ & $21.33 \pm 0.94$ & $28.50 \pm 2.96$ \\
\hline
\end{tabular}

TABLe 4: Tensile forces of the studied species.

\begin{tabular}{lccc}
\hline Plant species & \multicolumn{3}{c}{ Tensile force, $T_{f}(\mathrm{~N})$} \\
& Minimum & Maximum & Mean \\
\hline PPl & 1.06 & 9.33 & 4.88 \\
PPd & 1.14 & 8.51 & 4.57 \\
\hline
\end{tabular}

The relationship between the tensile force and root diameter for both species is shown in Figure 1. The scattered values of tensile force against root diameter for PPl species can best be represented by a power law equation:

$$
\begin{aligned}
T_{f} & =7.762 d^{1.1233}, \\
R^{2} & =0.893 .
\end{aligned}
$$

Meanwhile, the PPd species is represented by the following equation:

$$
\begin{aligned}
T_{f} & =7.0713 d^{1.489}, \\
R^{2} & =0.8611,
\end{aligned}
$$

where $T_{f}$ is in $\mathrm{N}$ and $d$ is in $\mathrm{mm}$.

Based on these results, the root tensile force values showed an increasing trend with increasing values in diameter of root. The relationship can be represented by both power law equation [60] and second-order polynomials [39]. The power law equation was applied since this equation represents the best fit line for the data and has been widely reported by many previous researches $[18,54,61]$. As shown in Figure 1, the relationship represented by the power law equation for both of the studied species was very closely presented due to the small variation in diameter of root. Higher tensile strength capacity of root exhibits better resistance to tensional force that develops during slope failure [31]. Plant roots intercept the potential failure plane by binding ground/soil surface and failure plane together [62]. Root density, network, and types can further enhance the existing stability throughout root anchorage of the particular soil slope $[63,64]$. In addition, the presence of higher root tensile resistance can contribute to the increased density of grass on the slope and more resistance toward overturning $[1,6]$. Teerawattanasuk et al. [54] also mentioned the contribution of fiber on tensile strength for the tested root which varied in different species and growing period. The influence of cellulose and lignin contents on tensile strength has been comprehensively studied by Genet et al. [16] and Zhang et al. [17]. They found that the thinner root diameter attributed to stronger tensile strength as a result of the cellulose and lignin contents which subsequently add to slope stability. The effect of moisture content on tensile strength of root was also discussed by Zhang et al. [61] and Noorasyikin and Zainab [65]. 


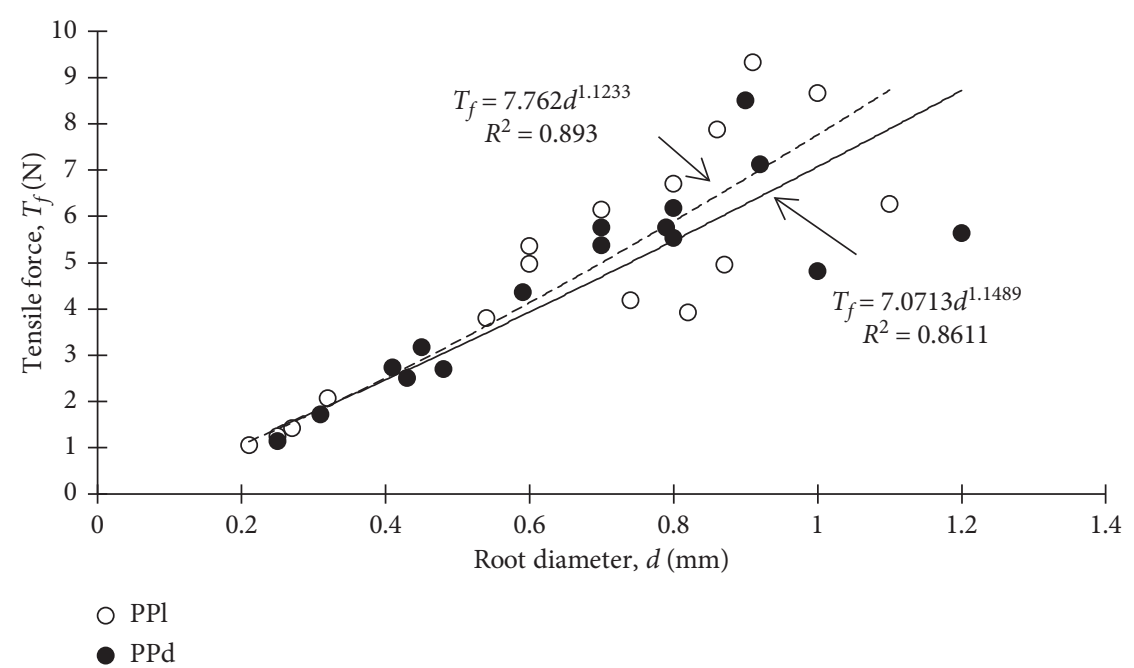

FIGURE 1: Relationships between root tensile force $(\mathrm{N})$ and root diameter $(\mathrm{mm})$. Black solid line $=$ PPd; dashed line $=$ PPl.

3.3. Direct Shear Box Test. The shear stress-displacement curves from the direct shear box test for both studied species are shown in Figure 2. Table 5 shows the summary of the shear strength parameters and available biomass of each test. Generally, the shear stresses increase linearly at early displacement (less than $1.0 \mathrm{~mm}$ ) before achieving their maximum shear stresses. As the applied normal stress increases, the values of maximum strength also increase. At applied normal stress $10 \mathrm{kPa}$, the maximum shear stress was $8.40 \mathrm{kPa}$ for the PPl species. The maximum shear stress at greater applied normal stresses at $20 \mathrm{kPa}$ and $30 \mathrm{kPa}$ increased to $11.30 \mathrm{kPa}$ and $19.09 \mathrm{kPa}$, respectively (Figure 2).

The results showed that the root-permeated soil of both species displayed higher soil shear strength values than the root-free soil (control) (Figure 3). In comparison, the PPI species demonstrated higher value of soil shear strength than PPd species. The cohesion values for the PPl and PPd species were $7.5 \mathrm{kPa}$ and $6.1 \mathrm{kPa}$, respectively. As expected, the cohesion value for control was lower than root-permeated soil sample (Table 5).

The contribution of root biomass to the maximum shear stress was clearly observed in PPl and PPd species. As shown in Table 5, PPl species presents higher value of average of biomass content $(0.146 \mathrm{~g})$ than PPd species $(0.058 \mathrm{~g})$. The internal friction angle $\theta$ for the root-permeated soil of PPl and PPd species showed higher values than the control sample. The friction angle $\theta$ for the PPl species was $21.3^{\circ}$ while for the control it was $10.7^{\circ}$. The different values between PPl and PPd with the control were $10.6^{\circ}$ and $1.8^{\circ}$, respectively.

The increase in the soil shear strength of root-permeated soil is clearly influenced by the presence of root biomass. In comparison, the average biomass for the PPl species is higher than PPd species which corresponds to the higher shear strength. However, the increase in shear strength of soil can also be associated with the matric suction and root-shoot ratio [66]. They found that the plant induced suction can be enhanced with increasing root biomass (plant maturity or biodiversity).
The increase in shear strength is due to the presence of roots, which interact with soil that occurred at relatively balanced increases in cohesion values and internal friction angles. However, the cohesion parameter was mostly influenced by the presence of roots [67]. A higher root biomass of root-permeated soil can improve the cohesion and friction values which overall increase the shear strength of the soil. Meanwhile, lower biomass content is associated with low cohesion and friction. These reflect how the root content is one of the main important factors in reinforcement of soil $[68,69]$. The presence of roots has an effect on the internal friction angle value between two selected species (Table 3). As stated early, the change in internal friction can be explained in terms of the root biomass. Both species exhibited different amount of biomass that significantly resulted with friction angle. The friction angle value of PPl species is approximately $70 \%$ higher than PPd species. The frictional angle values in this present study were smaller than the value for sandy soil (Table 5). Similarly, Maffra et al. [67] performed a study on the effect of root on sandy soil shear strength using Phyllanthus sellowianus. They found the friction angle was $29.01^{\circ}$ for root-permeated soil and $27.4^{\circ}$ for soil without root (control). On the other hand, internal friction angle of the root-soil composite system for Artemisia ordosica (Artemisia ordosica Krasch.) is higher than the angle of the soil without Artemisia ordosica Krasch roots, $10.26^{\circ}$ and $8.95^{\circ}$, respectively [70]. According to Veylon et al. [71], this could be due to several factors such as type of soil, sample size, and methods of sample preparation. It has also been reported that there is a link between the small amount of roots and insignificant effect on internal friction [67, 71].

Studies have shown that the mean values of root per unit area of soil at shallow layers are lower than $1 \%[72,73]$. This small proportion of roots over the soil block seems to justify why few roots have experienced little change in their particle arrangement, thus subsequently having minor effect on the internal friction angle [67]. The influence of root on internal friction angle was also performed by Graf et al. [74]. They found that planted soil exhibited a higher internal friction 


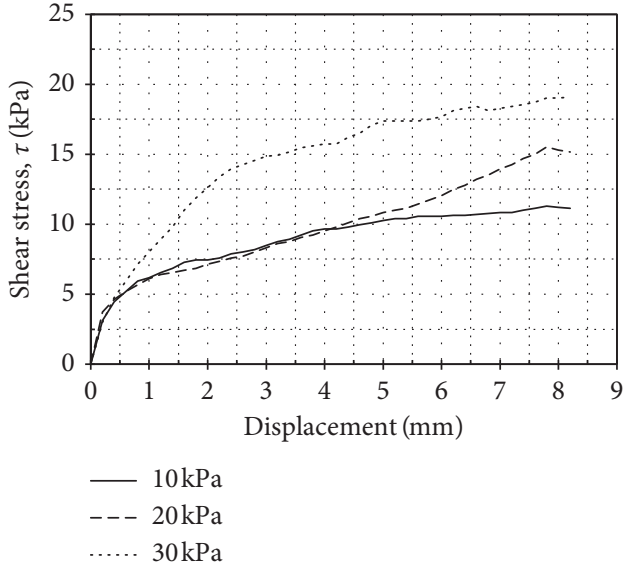

(a)

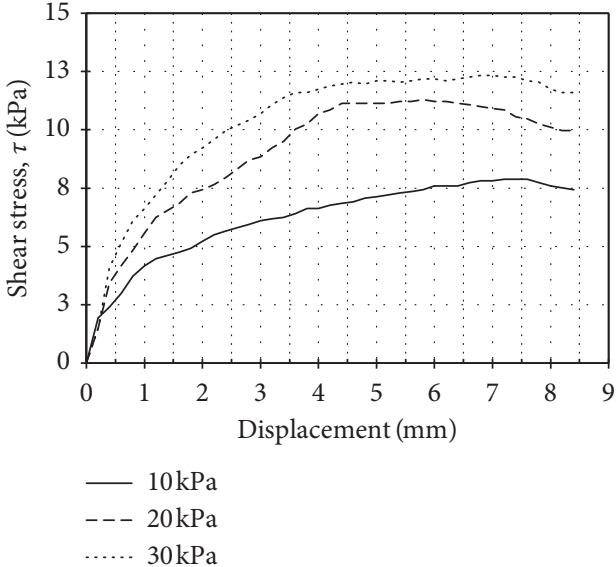

(b)

FIgURE 2: Shear stress against displacement curves for direct shear tests on three different normal loads of (a) PPl and (b) PPd species.

TABLE 5: Summary of the shear strength parameters and biomass of different planted soils at different values of normal pressure.

\begin{tabular}{|c|c|c|c|c|c|}
\hline Species studied & Normal pressure $(\mathrm{kPa})$ & Max. shear stress $(\mathrm{kPa})$ & Average biomass (g) & Cohesive value $c(\mathrm{kPa})$ & Friction angle $\theta\left({ }^{\circ}\right)$ \\
\hline \multirow{3}{*}{ PPl } & 10 & 11.3 & \multirow{3}{*}{0.146} & \multirow{3}{*}{7.5} & \multirow{3}{*}{21.3} \\
\hline & 20 & 15.5 & & & \\
\hline & 30 & 19.0 & & & \\
\hline \multirow{3}{*}{ PPd } & 10 & 7.8 & \multirow{3}{*}{0.058} & \multirow{3}{*}{6.1} & \multirow{3}{*}{12.5} \\
\hline & 20 & 11.2 & & & \\
\hline & 30 & 12.3 & & & \\
\hline \multirow{3}{*}{ Control } & 10 & 6.4 & \multirow{3}{*}{$\mathrm{NA}^{*}$} & \multirow{3}{*}{4.2} & \multirow{3}{*}{10.7} \\
\hline & 20 & 8.4 & & & \\
\hline & 30 & 11.5 & & & \\
\hline
\end{tabular}

${ }^{*} \mathrm{NA}=$ not available (no plant).

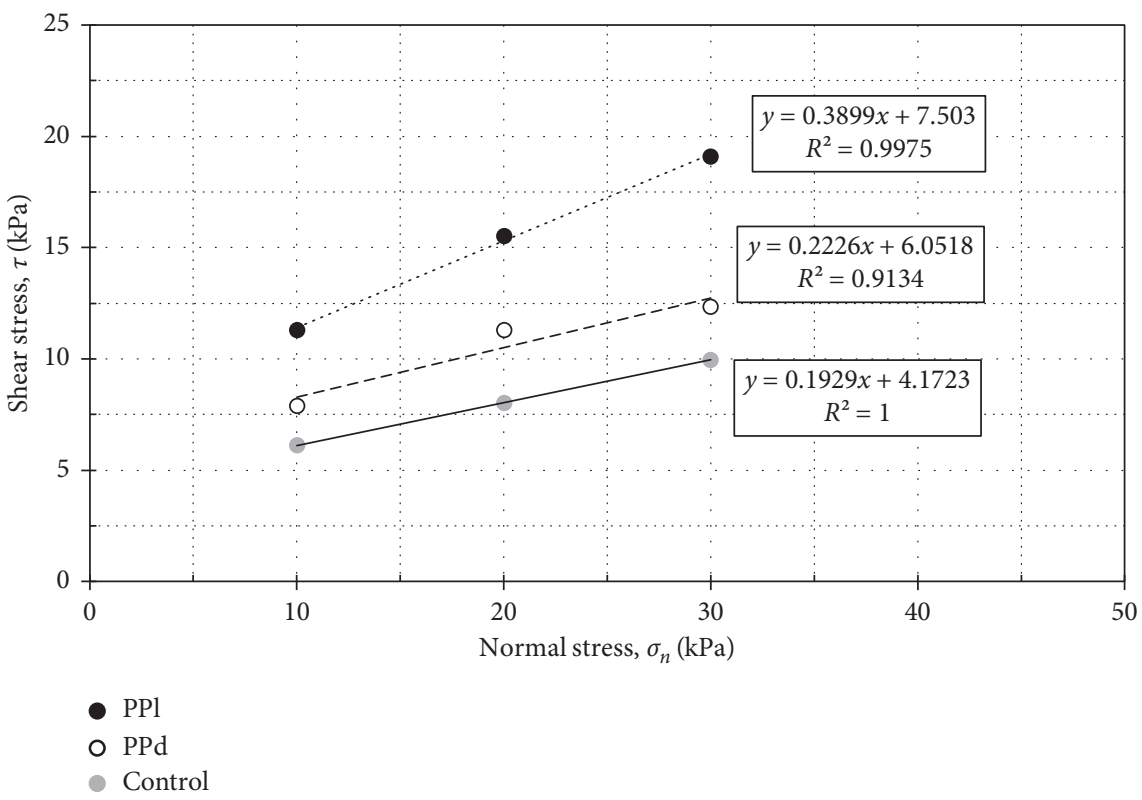

FIGURE 3: Relationship between shear strength and normal stress of control (bare soil) and root-penetrated soil after 6 months of growth.

value $\left(\theta=39.4^{\circ}\right.$, unit weight, $\left.\gamma=15.5 \mathrm{kN} / \mathrm{m}^{3}\right)$ than untreated soil at the same unit weight $\left(\theta=34.3^{\circ}\right)$. By increasing the unit weight $\gamma$, from $15.5 \mathrm{kN} / \mathrm{m}^{3}$ to $19 \mathrm{kN} / \mathrm{m}^{3}$, the internal friction angle for untreated soil rose up to $40.1^{\circ}$. Similarly, synthetic fibers were used to mimic the function of root in soils apparently showing higher shear strength than bare soil 
$[75,76]$. Small amount of root can greatly influence the value of soil cohesion. The soil cohesion increases as the roots intercept the potential failure surface, which can result in rupture or slip of the fibers when the roots are subjected to further shear force [2, 77].

\section{Conclusions}

This study investigated the effects of the grass species, namely, $P$. polystachion and $P$. pedicellatum, on the root tensile resistance and soil shear strength of root-permeated soils. The results of root tensile force increased with increasing the root diameter for both studied species of Pennisetum. The relationship between root tensile force and root diameter was slightly different for both species, which could be due to small variation in root diameter. It was found that PPl showed higher root tensile force compared to PPd. This study showed that roots can significantly contribute to the soil shear strength. The root-permeated soils showed higher shear strength than control samples, which were zero plants. In comparison, again $\mathrm{PPl}$ exhibited higher values of shear strength than PPd. The results from this study were in agreement with the presence of root systems that can mechanically reinforce soil slope. Therefore, with the combined mechanical characteristics of root tensile and the influence of these selected plant species on soil shear strength, the stability of particular slope can be successfully improved. It is expected that the improvement of bioengineered slope gradually increases with the plant age. The use of selected Pennisetum spp. has never been adopted as a biological material for soil bioengineering approach as these species have several advantages due to their widely distribution, easily adaptation, and soil strength improvement.

\section{Data Availability}

The data used to support the findings of this study are available from the corresponding author upon request.

\section{Conflicts of Interest}

The authors declare that they have no conflicts of interest.

\section{Acknowledgments}

The authors would like to thank UKM for the financial support through research Grant no. GUP-2016-068. The authors also thank the laboratory assistant staff of Civil Engineering School of Faculty of Engineering and FORCE, UKM, for assisting the mechanical testing of root tensile and direct shear box tests.

\section{References}

[1] O. Normaniza, M. N. Abdullah, and C. H. Abdullah, "Pull-out and tensile strength properties of two selected tropical trees," Sains Malaysiana, vol. 40, no. 6, pp. 577-585, 2011.

[2] D. H. Gray and R. D. Sotir, Biotechnical and Soil Bioengineering Slope Stabilization: A Practical Guide for Erosion Control, John Wiley and Sons, Hoboken, NJ, USA, 1996.
[3] D. H. Gray and A. J. Leiser, Biotechnical Slope Protection and Erosion Control, Van Nostrand Reinhold, New York, NY, USA, 1982.

[4] O. Normaniza, H. A. Faisal, and S. S. Barakbah, "Engineering properties of Leucaena leucocephala for prevention of slope failure," Ecological Engineering, vol. 32, no. 3, pp. 215-221, 2008.

[5] R. R. Ziemer, "Roots and the stability of forested slopes," in Erosion and Sediment Transport in Pacific Rim Steeplands, T. R. H. Davies and A. J. Pearce, Eds., Vol. 343-361, IAHS, Christchurch, New Zealand, 1981.

[6] N. J. Coppin and I. G. Richards, Use of Vegetation in Civil Engineering, Butterworth, Oxford, UK, 1990.

[7] F. Preti and F. Giadrossich, "Root reinforcement and slope bioengineering stabilization by Spanish broom (Spartium junceum L.)," Hydrology and Earth System Sciences, vol. 13, no. 9, pp. 1713-1726, 2009.

[8] G. B. Bischetti, M. Di Fi Dio, and F. Florineth, "On the origin of soil bioengineering," Landscape Research, vol. 39, no. 5, pp. 583-595, 2014.

[9] F. Rey, C. Bifulco, G. B. Bischetti et al., "Soil and water bioengineering: practice and research needs for reconciling natural hazard control and ecological restoration," Science of the Total Environment, vol. 648, pp. 1210-1218, 2019.

[10] A. Stokes, I. Spanos, J. Norris, and L. H. Cammeraat, (Eds.). "Eco- and ground bioengineering: the use of vegetation to improve slope stability," in Developments in Plant and Soil Sciences, vol. 103, p. 460, Springer, Berlin, Germany, 2007.

[11] R. C. Sidle, M. Tani, and A. D. Ziegler, "Catchment processes in Southeast Asia: atmospheric, hydrologic, erosion, nutrient cycling, and management effects," Forest Ecology and Management, vol. 224, no. 1-2, pp. 1-4, 2006.

[12] E. Abdi, B. Majnounian, H. Rahimi, and M. Zobeiri, "Distribution and tensile strength of Hornbeam (Carpinus betulus) roots growing on slopes of Caspian Forests, Iran," Journal of Forestry Research, vol. 20, no. 2, pp. 105-110, 2009.

[13] G. B. Chirico, M. Borga, P. Tarolli, R. Rigon, and F. Preti, "Role of vegetation on slope stability under transient unsaturated conditions," Procedia Environmental Sciences, vol. 19, pp. 932-941, 2013.

[14] M. N. Wuddivira, R. J. Stone, and E. I. Ekwue, "Influence of cohesive and disruptive forces on strength and erodibility of tropical soil," Soil and Tillage Research, vol. 133, pp. 40-48, 2013.

[15] K. H. Eab, S. Likitlersuang, and A. Takahashi, "Laboratory and modelling investigation of root-reinforced system for slope stabilisation," Soils and Foundations, vol. 55, no. 5, pp. 1270-1281, 2015.

[16] M. Genet, A. Stokes, F. Salin et al., "The influence of cellulose content on tensile strength in tree roots," Plant and Soil, vol. 278, no. 1-2, pp. 1-9, 2005.

[17] C.-B. Zhang, L.-H. Chen, and J. Jiang, "Why fine tree roots are stronger than thicker roots: the role of cellulose and lignin in relation to slope stability," Geomorphology, vol. 206, pp. 196-202, 2014.

[18] C. Mattia, G. B. Bischetti, and F. Gentile, "Biotechnical characteristics of root systems of typical Mediterranean species," Plant and Soil, vol. 278, no. 1-2, pp. 23-32, 2005.

[19] T. H. Wu, "Investigations of landslides on prince of Wales Island Geotechnical engineering," Rep. 5, Department of Civil Engineering, Ohio State University, Columbus, OH, USA, 1976.

[20] L. J. Waldron, "The shear resistance of root-permeated homogeneous and stratified soil," Soil Science Society of America Journal, vol. 41, no. 5, pp. 843-849, 1977. 
[21] Z. Mao, L. Saint-André, M. Genet et al., "Engineering ecological protection against landslides in diverse mountain forests: choosing cohesion models," Ecological Engineering, vol. 45, pp. 55-69, 2012.

[22] S. De Baets, J. Poesen, B. Reubens, K. Wemans, J. De Baerdemaekaer, and B. Muys, "Root tensile strength and root distribution of typical Mediterranean plant species and their contribution to soil shear strength," Plant and Soil, vol. 305, no. 1-2, pp. 207-226, 2008.

[23] C.-C. Fan and Y.-W. Chen, "The effect of root architecture on the shearing resistance of root-permeated soils," Ecological Engineering, vol. 36, no. 6, pp. 813-826, 2010.

[24] S. P. Sati and Y. P. Sundiyal, "Role of some tree species in slope instability," Himalayan Geology, vol. 28, no. 1, pp. 75-78, 2007.

[25] M. Saifuddin and O. Normaniza, "Rooting characteristics of some tropical plants for slope protection," Journal of Tropical Forest Science, vol. 28, no. 4, pp. 469-478, 2016.

[26] A. Mulyono, A. Subardja, I. Ekasari, M. Lailati, R. Sudirja, and W. Ningrum, "The hydromechanics of vegetation for slope stabilization," IOP Conference Series: Earth and Environmental Science, vol. 118, pp. 1-6, 2018.

[27] J. H. Kim, T. Fourcaud, C. Jourdan et al., "Vegetation as a driver of temporal variations in slope stability: the impact of hydrological processes," Geophysical Research Letters, vol. 44, no. 10, pp. 4897-4907, 2017.

[28] A. K. Leung and C. W. W. Ng, "Analyses of groundwater flow and plant evapotranspiration in a vegetated soil slope," $\mathrm{Ca}$ nadian Geotechnical Journal, vol. 50, no. 12, pp. 1204-1218, 2013.

[29] A. Schnitzlera, W. H. Brack, and M. A. Esther, "Examining native and exotic species diversity in European riparian forests," Biological Conservation, vol. 38, no. 1-2, pp. 146-156, 2007.

[30] O. Normaniza and S. S. Barakabah, "The effect of plant succession on slope stability," Ecological Engineering, vol. 37, no. 2, pp. 139-147, 2011.

[31] A. Stokes, C. Atger, A. G. Bengough, T. Fourcaud, and R. C. Sidle, "Desirable plant root traits for protecting natural and engineered slopes against landslides," Plant and Soil, vol. 324, no. 1-2, pp. 1-30, 2009.

[32] R. D. Lasamadi, S. S. Malalantang, Rustandi, and S. D. Anis, "Pertumbuhan dan perkembangan rumput gajah dwarf (Pennisetum purpureum cv. Mott) yang diberi pupuk organik hasil Fermentasi Em 4 ," ZOOTEC, vol. 32, no. 5, pp. 158-171, 2013.

[33] S. O. Oshunsanya and O. O. Aliku, "Vetiver grass: a tool for sustainable agriculture," in Grasses-Benefits, Diversities and Functional Roles, IntechOpen, London, UK, 2017.

[34] L. Giupponi, G. Borgonovo, A. Giorgi, and G. B. Bischetti, "How to renew soil bioengineering for slope stabilization: some proposals," Landscape and Ecological Engineering, vol. 15, no. 1, pp. 37-50, 2019.

[35] B. S. Ismail, P. W. Tan, and T. S. Chuah, "Assessment of the potential allelopathic effects of pennisetum purpureum schumach. On the germination and growth of eleusine indica (L.) gaertn," Sains Malaysiana, vol. 44, no. 2, pp. 269-274, 2015.

[36] E. O. E Afaff, J. H. Adam, A. R. Zulfahmi et al., "Preliminary study on effect fertilizer with two different NPK combinations on brachiaria decumbens growth performance," in Proceedings of the 14th Symposium of Malaysian Society of Applied Biology, pp. 38-45, Malacca, Malaysia, 2016.

[37] C. Vergani, E. A. Chiaradia, and G. B. Bischetti, "Variability in the tensile resistance of roots in Alpine forest tree species," Ecological Engineering, vol. 46, pp. 43-56, 2012.
[38] G. B. Bischetti, E. A. Chiaradia, T. Epis, and E. Morlotti, "Root cohesion of forest species in the Italian Alps," Plant and Soil, vol. 324, no. 1-2, pp. 71-89, 2009.

[39] K. M. Schmidt, J. J. Roering, J. D. Stock, W. E. Dietrich, D. R. Montgomery, and T. Schaub, "The variability of root cohesion as an influence on shallow landslide susceptibility in the Oregon coast range," Canadian Geotechnical Journal, vol. 38, no. 5, pp. 995-1024, 2001.

[40] M. Tosi, "Root tensile strength relationships and their slope stability implications of three shrub species in the Northern Apennines (Italy)," Geomorphology, vol. 87, no. 4, pp. 268283, 2007.

[41] M. Genet, M. Li, T. Luo, T. Fourcaud, A. Clément-Vidal, and A. Stokes, "Linking carbon supply to root cell-wall chemistry and mechanics at high altitudes in Abies georgei," Annals of Botany, vol. 107, no. 2, pp. 311-320, 2011.

[42] E. Abdi, B. Majnounian, M. Genet, and H. Rahimi, "Quantifying the effects of root reinforcement of Persian Ironwood (Parrotia persica) on slope stability; a case study: hillslope of Hyrcanian forests, northern Iran," Ecological Engineering, vol. 36, no. 10, pp. 1409-1416, 2010.

[43] M. Genet, A. Stokes, T. Fourcaud, and J. E. Norris, "The influence of plant diversity on slope stability in a moist evergreen deciduous forest," Ecological Engineering, vol. 36, no. 3, pp. 265-275, 2010.

[44] E. Comino, P. Marengo, and V. Rolli, "Root reinforcement effect of different grass species: a comparison between experimental and models results," Soil and Tillage Research, vol. 110 , no. 1, pp. 60-68, 2010.

[45] M. Burylo, C. Hudek, and F. Rey, "Soil reinforcement by the roots of six dominant species on eroded mountainous marly slopes (Southern Alps, France)," Catena, vol. 84, no. 1-2, pp. 70-78, 2011.

[46] ASTM D 3379-75, "Standard test method for tensile strength and young's modulus for high modulus single-filament materials," Annual Book of ASTM Standards, vol. 8, pp. 128-131, ASTM International, West Conshohocken, PA, USA, 1989.

[47] T. H. Wu, W. P. McKinnell, and D. N. Swanston, "Strength of tree roots and landslides on prince of Wales Island, Alaska," Canadian Geotechnical Journal, vol. 16, no. 1, pp. 19-33, 1979.

[48] British Standards Institute, BS 1377, Methods of test for soil for civil engineering purposes-Part 7: Shear Strength Tests (Total Stress), Vol. 62, British Standards Institute, London, UK, 1990.

[49] M. Saifuddin, N. Osman, M. Motior Rahman, and A. N. Boyce, "Soil reinforcement capability of two legume species from plant morphological traits and mechanical properties," Current Science, vol. 108, no. 7, pp. 1340-1347, 2015.

[50] R. Naghdi, S. Maleki, E. Abdi, R. Mousavi, and M. Nikooy, "Assessing the effect of Alnus roots on hillslope stability in order to use in soil bioengineering," Journal of Forest Science, vol. 59, no. 11, pp. 417-423, 2013.

[51] A. Cislaghi, E. A. Chiaradia, and G. B. Bischetti, "Including root reinforcement variability in a probabilistic 3D stability model," Earth Surface Processes and Landforms, vol. 42, no. 12, pp. 1789-1806, 2017.

[52] T. H. Wu, "Root reinforcement of soil: review of analytical models, test results, and applications to design," Canadian Geotechnical Journal, vol. 50, no. 3, pp. 259-274, 2013.

[53] J. J. Roering, K. M. Schmidt, J. D. Stock, W. E. Dietrich, and D. R. Montgomery, "Shallow landsliding, root reinforcement, and the spatial distribution of trees in the Oregon coast range," Canadian Geotechnical Journal, vol. 40, no. 2, pp. 237-253, 2003. 
[54] C. Teerawattanasuk, J. Maneecharoen, D. T. Bergado, P. Voottipruex, and G. L. Le, "Root strength measurements of vetiver and ruzi grasses," Lowland Technology International, vol. 16, no. 2, pp. 71-80, 2014.

[55] X. Kan, J. Cheng, X. Hu, F. Zhu, and M. Li, "Effects of grass and forests and the infiltration amount on preferential flow in karst regions of China," Water, vol. 11, no. 8, pp. 1-19, 2019.

[56] N. Somaratne, "Characteristics of point recharge in karst aquifers," Water, vol. 6, no. 9, pp. 2782-2807, 2014.

[57] X.-P. Wang, X.-R. Li, H.-L. Xiao, R. Berndtsson, and Y.-X. Pan, "Effects of surface characteristics on infiltration patterns in an arid shrub desert," Hydrological Processes, vol. 21, no. 1, pp. 72-79, 2007.

[58] K. Burri, F. Graf, and A. Böll, "Revegetation measures improve soil aggregate stability: a case study of a landslide area in Central Switzerland," Forest Snow and Landscape Research, vol. 82, pp. 45-60, 2009.

[59] A. Cislaghi, L. Giupponi, A. Tamburini, A. Giorgi, and G. B. Bischetti, "The effects of mountain grazing abandonment on plant community, forage value and soil properties: observations and field measurements in an alpine area," CATENA, vol. 181, Article ID 104086, 2019.

[60] F. Giadrossich, D. Cohen, M. Schwarz et al., "Modeling bioengineering traits of Jatropha curcas L," Ecological Engineering, vol. 89, pp. 40-48, 2016.

[61] C. Zhang, X. Zhou, J. Jiang, Y. Wei, J. Ma, and P. D. Hallett, "Root moisture content influence on root tensile tests of herbaceous plants," Catena, vol. 172, pp. 140-147, 2019.

[62] M. Ghestem, K. Cao, W. Ma et al., "A framework for identifying plant species to be used as 'ecological engineers' for fixing soil on unstable slopes," PLoS One, vol. 9, no. 8, Article ID e95876, 2014.

[63] L. Dupuy, T. Fourcaud, and A. Stokes, "A numerical investigation into factors affecting the anchorage of roots in tension," European Journal of Soil Science, vol. 56, no. 3, pp. 319-327, 2005.

[64] S. B. Mickovski, R. Sonnenberg, M. F. Bransby et al., "Shear reinforcement of soil by vegetation," in Proceedings of the XIVth European Conference on Soil Mechanics and Geotechnical Engineering, Millpress Science Publishers, Madrid, Spain, 2007.

[65] M. N. Noorasyikin and M. Zainab, "Tensile strength of Bermuda grass and vetiver grass in terms of root reinforcement ability toward soil slope stabilization," IOP Conference Series: Materials Science and Engineering, vol. 136, pp. 1-8, 2016.

[66] A. Yildiz, F. Graf, and S. M. Springman, "An investigation of plant-induced suction and its implications for slope stability," Proceedings of the Institution of Civil Engineers-Geotechnical Engineering, vol. 172, no. 6, pp. 520-529, 2019.

[67] C. Maffra, R. Sousa, F. Sutili, and R. Pinhero, "The effect of roots on the shear strength of texturally distint soils," Floresta e Ambience, vol. 26, no. 3, pp. 1-11, 2019.

[68] M. N. Abdullah, N. Osman, and A. Faisal, "Soil-root shear strength properties of some slope plants," Sains Malaysiana, vol. 40, pp. 1065-1073, 2011.

[69] N. Pollen-Bankhead and A. Simon, "Hydrologic and hydraulic effects of riparian root networks on streambank stability: is mechanical root-reinforcement the whole story?" Geomorphology, vol. 116, no. 3-4, pp. 353-362, 2010.

[70] R. Xu, X. Li, W. Yang, C. Jiang, and M. Rabiei, "Use of local plants for ecological restoration and slope stability: a possible application in Yan'an, Loess Plateau, China," Geomatics, Natural Hazards and Risk, vol. 10, no. 1, pp. 2106-2128, 2019.
[71] G. Veylon, M. Ghestem, A. Stokes, and A. Bernard, "Quantification of mechanical and hydric components of soil reinforcement by plant roots," Canadian Geotechnical Journal, vol. 52, no. 11, pp. 1839-1849, 2015.

[72] B. Abernethy and I. D. Rutherfurd, "The distribution and strength of riparian tree roots in relation to riverbank reinforcement," Hydrological Processes, vol. 15, no. 1, pp. 63-79, 2001.

[73] E. Comino and A. Druetta, "In situ shear tests of soil samples with grass root in Alpine environment," American Journal of Environmental Sciences, vol. 5, no. 4, pp. 475-486, 2009.

[74] F. Graf, M. Frei, and A. Böll, "Effects of vegetation on the angle of internal friction of a moraine," Forest Snow Landscape Research, vol. 82, pp. 61-77, 2009.

[75] H. Jiang, Y. Cai, and J. Liu, "Engineering properties of soild reinforced by short discrete polypropylene fiber," Journal of Materials in Civil Engineering, vol. 22, no. 12, pp. 1315-1322, 2010.

[76] M. Moradi, A. Hamidi, and G. Tavakoli Mehrjardi, "Shear strength of fiber-reinforced clay sands," Journal of Engineering Geology, vol. 10, no. 4, pp. 3767-3792, 2017.

[77] M. Schwarz, F. Preti, F. Giadrossich, P. Lehmann, and D. Or, "Quantifying the role of vegetation in slope stability: a case study in Tuscany (Italy)," Ecological Engineering, vol. 36, no. 3, pp. 285-291, 2010. 